\title{
A hospital-wide evaluation of delirium prevalence and outcomes in acute care patients - a cohort study
}

Maria Schubert ${ }^{1,2,3^{*}} \mathbb{D}$, Roger Schürch ${ }^{4,5}$, Soenke Boettger ${ }^{6}$, David Garcia Nuñez ${ }^{6,7}$, Urs Schwarz $^{8}$, Dominique Bettex ${ }^{9}$, Josef Jenewein ${ }^{6}$, Jasmina Bogdanovic ${ }^{1}$, Marina Lynne Staehli ${ }^{10}$, Rebecca Spirig ${ }^{11,2}$ and Alain Rudiger ${ }^{9}$

\begin{abstract}
Background: Delirium is a well-known complication in cardiac surgery and intensive care unit (ICU) patients. However, in many other settings its prevalence and clinical consequences are understudied. The aims of this study were: (1) To assess delirium prevalence in a large, diverse cohort of acute care patients classified as either at risk or not at risk for delirium; (2) To compare these two groups according to defined indicators; and (3) To compare delirious with nondelirious patients regarding hospital mortality, ICU and hospital length of stay, nursing hours and cost per case.

Methods: This cohort study was performed in a Swiss university hospital following implementation of a delirium management guideline. After excluding patients aged $<18$ years or with a length of stay (LOS) $<1$ day, $29^{\prime} 278$ patients hospitalized in the study hospital in 2014 were included.

Delirium period prevalence was calculated based on a Delirium Observation Scale (DOS) score $\geq 3$ and / or Intensive Care Delirium Screening Checklist (ICDSC) scores $\geq 4$.

Results: Of $10^{\prime} 906$ patients admitted, DOS / ICDSC scores indicated delirium in 28.4\%. Delirium was most prevalent (36.2-40.5\%) in cardiac surgery, neurosurgery, trauma, radiotherapy and neurology patients. It was also common in geriatrics, internal medicine, visceral surgery, reconstructive plastic surgery and cranio-maxillo-facial surgery patients (prevalence 21.6-28.6\%). In the unadjusted and adjusted models, delirious patients had a significantly higher risk of inpatient mortality, stayed significantly longer in the ICU and hospital, needed significantly more nursing hours and generated significantly higher costs per case. For the seven most common ICD-10 diagnoses, each diagnostic group's delirious patients had worse outcomes compared to those with no delirium.

Conclusions: The results indicate a high number of patients at risk for delirium, with high delirium prevalence across all patient groups. Delirious patients showed significantly worse clinical outcomes and generated higher costs. Subgroup analyses highlighted striking variations in delirium period-prevalence across patient groups. Due to the high prevalence of delirium in patients treated in care centers for radiotherapy, visceral surgery, reconstructive plastic surgery, cranio-maxillofacial surgery and oral surgery, it is recommended to expand the current focus of delirium management to these patient groups.
\end{abstract}

Keywords: Delirium, Neurocognitive disorders, Hospital mortality, Length of stay, Cost of diseases OR economic burden of diseases

\footnotetext{
* Correspondence: maria.schubert@unibas.ch; maria.schubert@zhaw.ch

${ }^{1}$ Nursing Science, Faculty of Medicine, Department of Public Health,

University of Basel, Bernoullistr. 28, 4056 Basel, Switzerland

2Directorate of Nursing/MTT, Insel Gruppe, University Hospital Inselspital,

Bern, Freiburgstr. 44a, 3010 Bern, Switzerland

Full list of author information is available at the end of the article
}

(c) The Author(s). 2018 Open Access This article is distributed under the terms of the Creative Commons Attribution 4.0 International License (http://creativecommons.org/licenses/by/4.0/), which permits unrestricted use, distribution, and reproduction in any medium, provided you give appropriate credit to the original author(s) and the source, provide a link to the Creative Commons license, and indicate if changes were made. The Creative Commons Public Domain Dedication waiver (http://creativecommons.org/publicdomain/zero/1.0/) applies to the data made available in this article, unless otherwise stated. 


\section{Background}

Delirium is a sudden acute mental change accompanying acute illness. Characterized by disturbances of consciousness, attention, cognition, psychomotor behavior and emotions [1, 2], it affects 10 to $60 \%$ of all patients treated in medical, surgical, medical-surgical mixed or general wards [3-5], and up to $80 \%$ of those treated in intensive care units (ICUs) [3, 6-10]. More than two dozen predisposing and precipitating delirium risk factors have been identified, including male gender, older age ( $>65$ years), prior delirium, co-morbidities (i.e., dementia, depression) and severe illness [3, 11-13].

Delirium is linked to negative patient and institutional outcomes including prolonged ICU and hospital length of stay (LOS) [7, 14-17], higher mortality rates [14, 16, 18-20], cognitive decline or impaired cognitive functions [20-23], restrictions in motor functionality [23, 24], ongoing need for care in long-term care institutions [14, 15] and a higher likelihood of discharge to destinations other than home $[23,25]$.

From an economic perspective, delirium is strongly associated with additional healthcare costs [17]. In the United States (US), annual additional delirium-related healthcare costs are estimated to range from 6.6 to 20.4 billion USD (mean: 9014 USD per case) in ICU patients [26] and 38 to 152 billion USD per year in non-ICU patients aged 70 years and older (range: 16,303 to 64,421 USD per case) [27].

The large number of patients affected by delirium during hospitalization, the negative clinical outcomes, and the severe economic consequences all call for action. In recent years, several delirium management guidelines and / or standardized programs were developed for the prevention, early recognition, and / or treatment of delirium across all hospital departments [28-32]. The results indicate that multicomponent delirium management guidelines or programs are most efficient to reduce the delirium rates and the delirium-linked negative outcomes, i.e., decreasing LOS and institutionalization [31, 33, 34].

In 2012, in response to the delirium burden at the study hospital -a Swiss university hospital-the multi-professional Delir-Path (Detect Evaluate Control Inpatient Risk factors, Prevent And Treat Hospital Acquired Deliriums) project was started. It includes a practice development part and a health service research (HSR) part.

Delir-Path has five primary purposes: 1) to develop a standardized multi-professional, multicomponent delirium management guideline for the prevention, early recognition and treatment of delirium; 2) to implement the delirium management guideline throughout the study hospital and to monitor and evaluate the implementation process based on defined outcomes; 3 ) to evaluate the effectiveness, efficiency, and benefits of the implemented multiprofessional delirium management protocol, both as a whole and as single components, e.g., pharmacological delirium treatment; 4) to develop and implement a system for monitoring delirium incidence rates and the courses of the underlying diseases (duration); 5) to develop and establish a multicenter, multiprofessional Health Care Service Research Program for effective, efficient and cost-effective delirium management.

As a first step in a form of a pilot study an interprofessional multicomponent delirium management guideline was developed. The developed guideline contains interventions for delirium prevention, risk stratification, screening and diagnostics, non-pharmacological and pharmacological treatment, as well as a multi-professional training program (see Additional file 1). The guideline was implemented on nine surgical and neurological wards and ICUs and its benefits evaluated $[35,36]$. Based on that pilot's promising results, the standardized delirium management guideline was adapted and implemented hospital-wide in 2013 / 2014 [35, 36]. Concurrently, the HSR program was developed further. In the study hospital, as of April 2018, this includes a main study, more than 10 sub-studies [6, 36-43]. Furthermore, the program includes a multicenter study in ICU settings. This study refers to the main study, which uses a longitudinal cohort design.

To date, delirium management programs and / or delirium bundles and related research have focused on the best-known high delirium risk patient groups - predominately ICU, cardiac and orthopaedic patients [3]. A small number have also focused on medical and / are palliative care groups $[44,45]$. However, the literature shows no delirium management programs implemented, e.g., for haemato-oncological patients, although, based on the typical courses of their conditions, fulfil the criteria for a high delirium risk [46].

Because significant risk groups may remain undetected, the Delir-Path main study included an entire university hospital cohort of acute care patients. This allowed us to study both delirium's prevalence and the effect of the implemented guideline across acute care patient groups.

\section{Methods}

\section{Aims}

The aims of this study were: (1) to assess delirium prevalence in a cohort of acute care patients classified as either at risk or not at risk for delirium; (2) to compare these two groups according to defined indicators, including main diagnosis, care center, and admission and discharge details; and (3) to compare delirious with non-delirious patients regarding hospital mortality, ICU and hospital LOS, nursing hours and cost per case.

\section{Study design and setting}

This study used data from the ongoing Delir-Path health service research program $[6,36-43]$ conducted in a Swiss 
university hospital with 800 beds distributed across 43 departments and institutes. As a longitudinal cohort study, it includes data of all eligible patients hospitalized in the study hospital between January and December 2014, 1 year after the implementation of the delirium guideline. Patients younger than 18 years of age, and those hospitalized for less than 1 day, were excluded (Fig. 1).

\section{Variables, measurements, data sources, data collection}

\section{Screening for and definition of delirium}

In accordance with the implemented delirium management guideline, all patients admitted to the regular wards were screened for delirium once per shift with the Delirium Observation Scale (DOS) [47] for at least 3 days, if they fulfilled the following criteria: a) $\geq$ 65 years; or b) $<65$ years with delirious symptoms, e.g., conspicuous symptoms such as disorientation or agitation. If the DOS Score indicated no delirium development for three consecutive days, the screening was stopped. If the patients developed a delirium, the screening was continued until the DOS score fell below 3 (see Additional file 1). All ICU patients with states of consciousness allowing assessment (Richmond Agitation Scale Score (RASS) [48] of -3 to +4 ) are screened once per shift with the Intensive Care Delirium Screening Checklist (ICDSC) [49] (see Additional file 1).

The DOS is a 13-item screening tool for non-ICU patients. It was developed to facilitate early recognition of delirium according to the criteria of the Diagnostic and Statistical Manual IV-TR. A DOS score $\geq 3$ indicates a delirium. The DOS's sensitivity $(82,89 \%)$ and specificity $(86,96 \%)$, as well as its reliability and validity were confirmed in several studies $[47,50,51]$.

The ICDSC is an 8-item screening tool developed to detect delirium in ICU patients, with scores $\geq 4$ indicating delirium [49]. In several studies, the tool has shown good sensitivity $(64,89,99 \%)$, specificity $(57,64,95 \%)$ and reliability (kappa 0.67, 0.91, 0.92) [38, 49, 52].

For the current study, a patient was considered delirious if he/she had at least once ICDSC score of $\geq 4$ and / or a DOS score $\geq 3$.

\section{Outcomes}

To describe the entire sample and to compare patients with and without delirium across patient subgroups, the following five main outcomes were selected: (1) Mortality, i.e., the frequency of patient deaths during hospitalization; (2) ICU LOS; (3) hospital LOS; (4) nursing hours per case, i.e., the

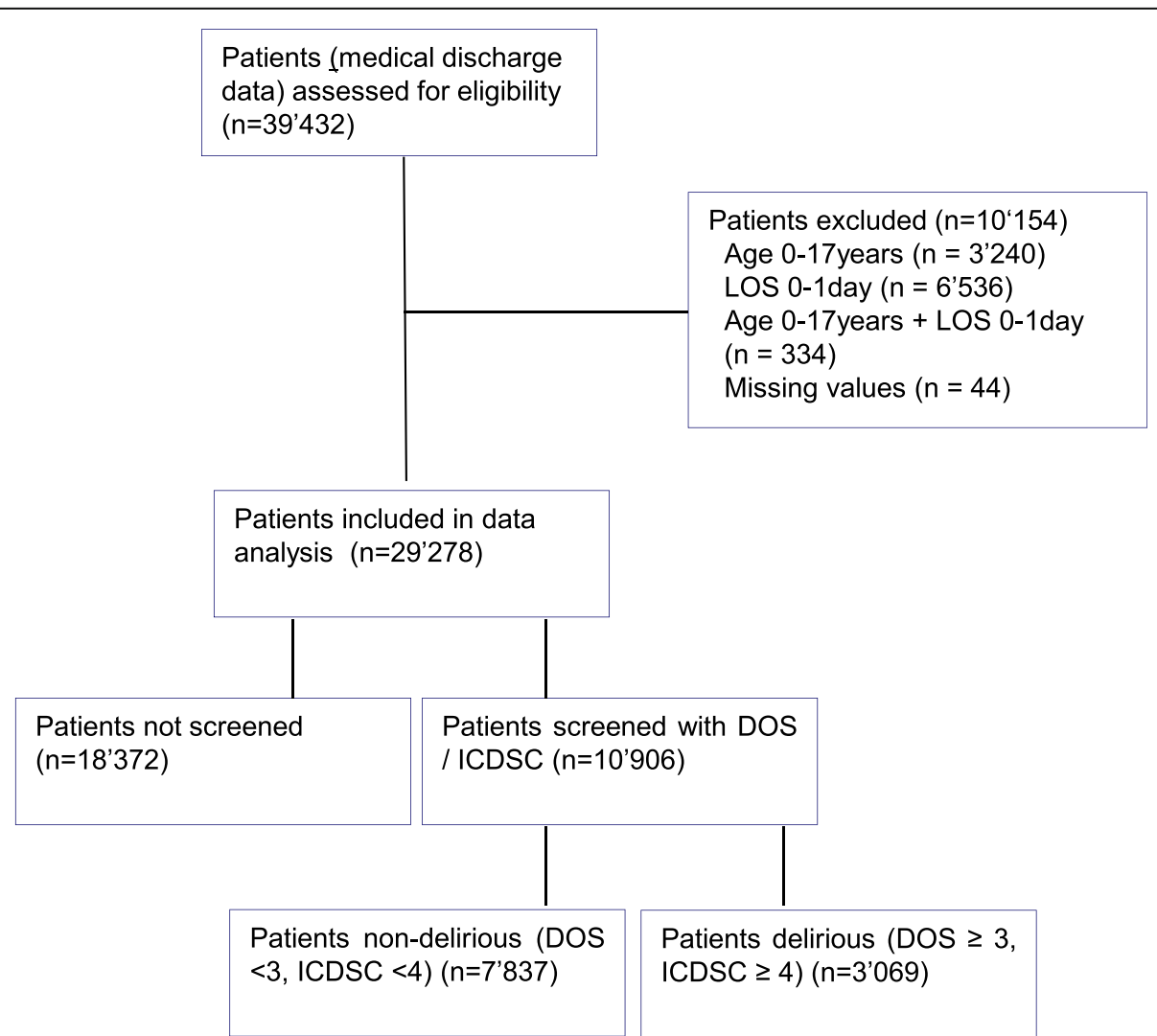

Fig. 1 Sample and sampling per intervention group of patients hospitalized in 2014. Legend: DOS (Delirium Observation Scale); ICDSC (Intensive Care Delirium Screening Checklist); LOS (Length of Stay) 
number of nursing hours spent per case for direct patient care, assessed once per shift; and (5) total cost per case.

Other outcomes of interest and variables used as patient descriptors or as control variables were age, gender, residency before admission to the hospital (e.g., home, hospital), type of hospital admission (emergency, other), care center (organizational unit: e.g. cardiac surgery, visceral surgery, internal medicine), principal diagnoses (diagnostic codes drawn from the 19 ICD-10 chapters, diagnoses other than delirium), comorbidities, the presence of one or more disorders (ICD- 10 codes) as defined by Quan et al., [53], length of ICU stay, discharge destination (the destination to which the patient was discharged from the hospital, i.e., home, other institution), and readmission rate.

All variables / data are documented regularly in the patient medical records. They refer to the following databases: the Swiss Federal Statistical Office (FSO) medical and administrative database [54], the Minimal Data SetIntensive Care Unit (MDSi) [55], the patient performance classification "Leistungserfassung in der Pflege" (LEP) [56] database, and DOS and ICDSC delirium screening data. The LEP performance classification is used for uniform documentation of services in the healthcare sector, and can be linked with other assessment, classification and outcome data. Authorized hospital administrative staff extracted the required patient data and made them available to the researchers. The researchers had no information that could be used to identify the patients from whom they had been collected. The data sets were linked based on unique case identification numbers.

\section{Statistical methods}

Patient characteristics for the entire sample and subgroups were described using means (with standard deviations), medians (with 25 and 75\% quartiles), or counts (and percentages).

We calculated the period prevalence as the ratio of the number of patients diagnosed with delirium over a given period to the number of eligible individuals in the hospitalized population during that period, presented as a percentage. We compared overall inpatient mortality of delirious to non-delirious patients using generalized linear models of the binomial family with logit link function. We compared ICU and hospital length of stays of delirious and non-delirious patients using Cox proportional hazard models. Finally, we compared costs per case and nursing hours using quantile regression. In an additional step, we adjusted these differences in mortality, LOS, cost and nursing hours by controlling for age, gender, pre-admission residence type, type of admission (emergency or not), Charlson co-morbidity index [53], type of service, and ICU stay (yes/no). In screened at-risk patients older than 65 years of age, we also performed an ICD-10 diagnosis subgroup analysis investigating differences between patients who developed delirium and those who did not. Five models analogous to the overall patient data set were constructed (i.e., one for each outcome variable). Contrasts were calculated 2. The two-sided level of significance was set at $P=0.05$. All statistical tasks were performed using the R Statistical Package v. 3.4.2. In R, we used the packages survival 2.41-3 for Cox proportional hazard models and quantreg 5.35 for quantile regressions. Additionally, we used lsmeans $2.27-61$ to calculate subgroup contrasts between delirious and non-delirious patients for GLMs and Cox proportional hazard models. Subgroup contrasts were calculated manually for quantile models, and significance was calculated based on standard errors following $[57,58]$.

\section{Results}

\section{Participants and their characteristics}

Of the $39^{\prime} 432$ patients hospitalized in the study hospital in 2014, 29'278 (74.2\%) were identified as eligible for this study and included in the analysis (Fig. 1). Characteristics of the overall patient sample (patients with vs. without delirium risk, delirious vs. non-delirious patients) are described in Table 1.

Whereas patients not at risk were generally admitted as elective (non-emergency) cases from home to the hospital, the screened patients, particularly those in delirious states, were more likely to have been transferred from another hospital and / or admitted via emergency admission. Post-admission, they were more likely to spend time in the ICU and more likely to be discharged to a rehabilitation center or another hospital (Table 1).

\section{Delirium prevalence in different patient subgroups (type of care, ICD-10 diagnosis)}

In accordance with the implemented guideline, 10'906 (37.2\%) of the total $29^{\prime} 278$ patients were identified at risk for delirium and screened. Of the screened group, 3'069 (28.1\%) yielded at least one DOS score $\geq 3$ and / or ICDSC score $\geq 4$, indicating a delirious state (Table 1 ). The number of delirious patients varied by type of care and ICD-10 diagnosis chapter. A delirious state was most frequent in internal / general medicine patients, followed, in descending order of prevalence, by cardiac surgery, neurology, neurosurgery and trauma surgery patients. This is partly reflected in the ICD-10 chapter groups, where delirium was more prevalent in patients with a principal diagnosis related to the ICD-10 chapters IX ("Diseases of circulatory system"), II ("Neoplasms") and XIX ("Injury/poisoning of external cause") (Table 1).

The comparisons within and across the various care units and ICD-10 chapter groups (Fig. 2) show that a delirious state was most frequent in patients admitted to cardiac 
Table 1 Characteristics of the patients: entire sample, patient at risk screened for a delirium, patient at risk with and without a delirious state

\begin{tabular}{|c|c|c|c|c|c|}
\hline \multirow[b]{2}{*}{ Endpoints / Variables } & \multicolumn{3}{|l|}{ Entire sample } & \multicolumn{2}{|c|}{$\begin{array}{l}\text { Screened sample - patient at risk for a } \\
\text { delirium }\end{array}$} \\
\hline & Total & $\begin{array}{l}\text { Not screened } \\
\text { (not at risk for a delirium) }\end{array}$ & $\begin{array}{l}\text { Screened } \\
\text { (at risk for a delirium) }\end{array}$ & $\begin{array}{l}\text { Non-delirious } \\
\text { DOS }<3 \text {, ICDSC }<4\end{array}$ & $\begin{array}{l}\text { Delirious } \\
\text { DOS } \geq 3, \operatorname{ICDSC} \geq 4\end{array}$ \\
\hline Total n (\%) & $29^{\prime} 278$ & $18^{\prime} 372(62.8)$ & 10'906 (37.2) & 7'837 (71.9) & $3^{\prime} 069(28.1)$ \\
\hline Age [years] mean (SD) & $54.7(19.2)$ & $47.0(16.9)$ & $67.6(15.4)$ & $67.3(15.2)$ & $68.4(15.8)$ \\
\hline Gender [male] n (\%) & $14^{\prime} 147(48.3)$ & 7'672 (41.8) & $6^{\prime} 475(59.4)$ & 4'601 (58.7) & 1'874 (61.1) \\
\hline \multicolumn{6}{|l|}{ Residency prior admission n (\%) } \\
\hline Home & $25^{\prime} 842(88.3)$ & $17^{\prime} 003(92.5)$ & 8'839 (81.0) & 6'730 (85.9) & 2'109 (68.7) \\
\hline Other hospital & 2'386 (8.1) & $928(5.1)$ & 1'458 (13.4) & $813(10.4)$ & $645(21.0)$ \\
\hline Nursing home & $402(1.4)$ & $121(0.7)$ & $281(2.6)$ & $125(1.6)$ & $156(5.1)$ \\
\hline Other residency & $462(1.6)$ & $245(1.3)$ & $217(2.0)$ & $99(1.3)$ & $118(3.8)$ \\
\hline With home care & $186(0.6)$ & $75(0.4)$ & $111(1.0)$ & $70(0.9)$ & $41(1.3)$ \\
\hline Emergency admission n (\%) & $13^{\prime} 862(47.3)$ & $8^{\prime} 727(47.5)$ & $5^{\prime} 135(47.1)$ & 3'280 (41.9) & 1'855 (60.4) \\
\hline \multicolumn{6}{|l|}{ Type of care $n(\%)$} \\
\hline Internal / general medicine & 7'198 (24.6) & 4'218 (23.0) & 2'980 (27.3) & 2'141 (27.3) & $839(27.3)$ \\
\hline Cardiac surgery & 1'392 (4.8) & $249(1.4)$ & 1'143 (10.5) & $680(8.7)$ & $463(15.1)$ \\
\hline Neurology & $1 ' 516(5.2)$ & $517(2.8)$ & $999(9.2)$ & $637(8.1)$ & $362(11.8)$ \\
\hline Neurosurgery & $968(3.3)$ & $173(0.9)$ & $795(7.3)$ & $480(6.1)$ & $315(10.3)$ \\
\hline Trauma surgery & 2'090 (7.1) & 1'360 (7.4) & $730(6.7)$ & $462(5.9)$ & $268(8.7)$ \\
\hline Other service & $16^{\prime} 114(55.0)$ & $11^{\prime} 855(64.5)$ & 4'259 (39.1) & 3'437 (43.9) & $822(26.8)$ \\
\hline \multicolumn{6}{|l|}{ ICD-10 chapter n (\%) } \\
\hline IX. Diseases of circulatory system & 4’538 (15.5) & 1'218 (6.6) & 3'320 (30.4) & $2^{\prime} 247(28.7)$ & $11^{\prime} 073(35.0)$ \\
\hline II. Neoplasms & $5^{\prime} 665(19.3)$ & 3'182 (17.3) & 2'483 (22.8) & 1'915 (24.4) & $568(18.5)$ \\
\hline XIX. Injury/poisoning of external cause & 2'997 (10.2) & 1'938 (10.5) & 1 '059 (9.7) & $653(8.3)$ & $406(13.2)$ \\
\hline XI. Diseases of the digestive system & 1'954 (6.7) & 1'326 (7.2) & $628(5.8)$ & $448(5.7)$ & $180(5.9)$ \\
\hline VI. Diseases of nervous system & $933(3.2)$ & $399(2.2)$ & $534(4.9)$ & $359(4.6)$ & $175(5.7)$ \\
\hline I. Infections/parasites & $728(2.5)$ & $492(2.7)$ & $236(2.2)$ & $120(1.5)$ & $116(3.8)$ \\
\hline X. Diseases of respiratory system & $1^{\prime} 440(4.9)$ & $966(5.3)$ & $474(4.3)$ & $367(4.7)$ & $107(3.5)$ \\
\hline Other ICD-10 chapters & $11, \mathbf{\prime} 023(37.6)$ & $8^{\prime} 851(48.2)$ & 2'172 (19.9) & $1 ' 728(22.0)$ & $444(14.5)$ \\
\hline ICU stay n (\%) & 4'002 (13.7 & $502(2.7)$ & 3'500 (32.1) & 1'912 (24.4) & 1'588 (51.7) \\
\hline \multicolumn{6}{|l|}{ Discharged n (\%) } \\
\hline Home & $23,679(80.9)$ & $16^{\prime} 767(91.3)$ & 6'912 (63.4) & 5'869 (74.9) & $1 ' 043(34.0)$ \\
\hline Rehab & 2'584 (8.8) & $521(2.8)$ & 2'063 (18.9) & 1'106 (14.1) & $957(31.2)$ \\
\hline Other hospital & $929(3.2)$ & $219(1.2)$ & $710(6.5)$ & $343(4.4)$ & $367(12.0)$ \\
\hline Nursing home & $599(2.0)$ & $190(1.0)$ & 409 (3.8) & $172(2.2)$ & $237(7.7)$ \\
\hline Others service & $266(0.9)$ & $120(0.7)$ & $146(1.3)$ & $57(0.7)$ & $89(2.9)$ \\
\hline Missing & $503(1.7)$ & $279(1.5)$ & $224(2.1)$ & $131(1.7)$ & $93(3.0)$ \\
\hline Re-admissions n (\%) & $910(3.1)$ & $546(3.0)$ & $364(3.3)$ & $252(3.2)$ & $112(3.6)$ \\
\hline \multicolumn{6}{|l|}{ Outcomes } \\
\hline Hospital mortality n (\%) & $718(2.5)$ & $276(1.5)$ & $442(4.1)$ & $159(2.0)$ & $283(9.2)$ \\
\hline $\begin{array}{l}\text { LOS in the hospital d median } \\
{[\mathrm{Q} 1, \text { Q3] }}\end{array}$ & $5.00[3,10]$ & $4[3,7]$ & $8[4,15$ & $7[4,12]$ & $13[7,23]$, \\
\hline $\begin{array}{l}\text { Nursing hours per case } \mathrm{h} \text { median } \\
{[\mathrm{Q} 1, \mathrm{Q} 3]}\end{array}$ & $30.1[17.7,59.5]$ & $24.1[15.7,39.9]$ & $52.5[26.0,107.7]$ & $41.0[22.2,76.0]$ & $114.5[56.7,240.5]$ \\
\hline Cost per case CHF & $\begin{array}{l}11^{\prime} 128 \\
{\left[6^{\prime} 667,22^{\prime} 861\right]}\end{array}$ & $\begin{array}{l}8^{\prime} 764 \\
{\left[5^{\prime} 788,14^{\prime} 515\right]}\end{array}$ & $\begin{array}{l}20^{\prime} 875 \\
{\left[10^{\prime} 463,42^{\prime} 271\right]}\end{array}$ & $\begin{array}{l}16^{\prime} 662 \\
{\left[9067,32^{\prime} 413\right]}\end{array}$ & $\begin{array}{l}40^{\prime} 259 \\
{\left[19^{\prime} 235,80^{\prime} 245\right]}\end{array}$ \\
\hline
\end{tabular}




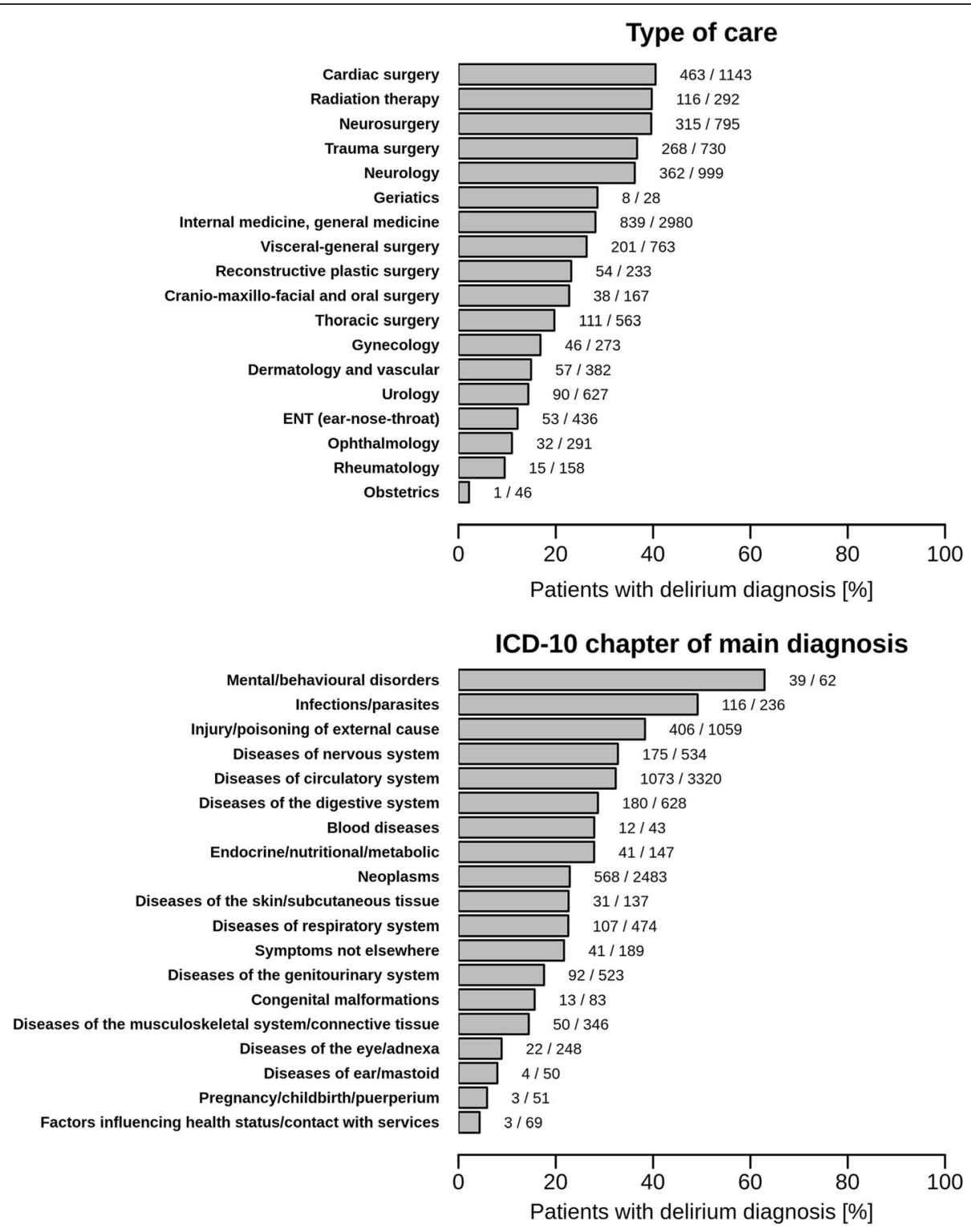

Fig. 2 Percentage of patients diagnosed with delirium (DOS, ICDSC scores) within type of care and ICD-10 chapter of main diagnosis. Legend/ notes: Patients with missing values were ignored when calculating percentages

surgery units $(40.5 \%)$, followed by radiotherapy $(39.7 \%)$, neurosurgery (39.6\%), trauma surgery $(36.7 \%)$ and neurology (36.2\%) care (Fig. 2). With reference to the ICD-10 chapters, delirium was most frequent in patients with a principal diagnosis related to group V ("Mental / behavioral disorders") (62.9\%), followed by groups I ("Infections/parasite diseases") (49.2\%), XIX ("Injury/poisoning/external causes") (38.3\%), VI ("Diseases of the nervous system") (32.8\%), IX ("Diseases of the circulatory system") (32.3\%), XI ("Diseases of the digestive system") (28.7\%), III ("Blood diseases") (27.9\%) and IV (Endocrine/nutritional/metabolic diseases) (27.9\%) (Fig. 2).
Mortality, ICU and hospital length of stay, mortality, cost and nursing hours per case in delirious and non-delirious patients

The comparison of the raw number of patients identified, in accordance with the implemented guideline, as not at risk for a delirium $\left(n=18^{\prime} 372\right)$ with those identified as at risk $\left(n=10^{\prime} 906\right)$ and screened shows that at-risk patients stayed twice as long in hospital, accounting for twice the number of nursing hours and twice the total cost per case. The comparison of the screened patients identified as not delirious $\left(n=7^{\prime} 837\right)$ versus delirious $\left(n=3^{\prime} 069\right)$ shows the same pattern (Table 1). 
In screened patients 65 years or older, cases with a delirium were at a higher risk of dying (crude mortality OR (95\% CI): 5.46 (4.85 to 6.15), $p<0.001$ ), stayed longer at the ICU (crude HR (95\% CI) for discharge: 0.40 (0.38 to $0.42), p<0.001)$ and in the hospital (crude HR (95\% CI) for discharge: 0.25 (0.24 to 0.26$), p<0.001)$, they caused more nursing hours (crude median difference nursing hours (95\% CI): 64.8 (62.0 to 67.6), $p<0.001$, and they cost more (crude median cost difference [in thousand CHF] (95\% CI): 20.9 (19.9 to 21.9), <0.001). If we adjusted for age, gender, pre-admission residence type, type of admission (emergency or not), Charlson co-morbidity index, type of service, and ICU stay, these differences were less pronounced, but still highly significant (adjusted mortality OR (95\% CI): 3.18 (2.79 to 3.63$), p$ $<0.001$; adjusted HR (95\% CI) for ICU discharge: 0.39 (0.36 to 0.41$), p<0.001$; adjusted HR (95\% CI) for hospital discharge: 0.43 (0.41 to 0.45$), p<0.001$; adjusted median difference nursing hours (95\% CI): 37.3 (35.0 to $39.5), p<0.001$; adjusted median cost difference [in thousand CHF] (95\% CI): 10.0 (9.3 to 10.6), < 0.001 ).

In our further exploration of the differences between non-delirious and delirious patients, only patients $\geq 65$ years who were judged at risk and screened for a delirium $\left(n=7^{\prime} 446\right)$ were included. Of these, 2'057 (38\%) were identified as delirious. (Table 2). For a comparison between the non-delirious and the delirious patients, a set of non-adjusted outcome models were fit across seven ICD-10 diagnoses groups with reference to the five selected outcomes (Table 2). Compared to non-delirious patients, those who were delirious were significantly more likely to die (3-11 times). They were also significantly less likely to be discharged from the ICU (1-9 times) or hospital (3-9 times). This applied to all patients except those with infectious diseases and diseases of the respiratory system: in their cases, the differences were not significant. Delirious patients also required significantly more nursing hours (1.5-4 times) and generated significantly higher costs per case (1.5 to 3.5 times) (Table 2). Differences in overall hospital LOS for screened patients with versus without delirium are displayed in Fig. 3.

\section{Discussion}

Of all eligible adult patients hospitalized in 2014, almost a third was identified as at risk for delirium and screened accordingly. Of those screened, nearly one-third yielded a DOS and / or ICDSC score indicating a delirium. In accordance with available evidence, delirium was more frequent in males and patients hospitalized for cardiac surgery $[3,6,59,60]$, neurosurgery, traumatology, radiotherapy, and neurological care, with period-prevalences from 36.2 to $40.5 \%$. Elsewhere, with period-prevalence's ranging from 21.6 to $28.6 \%$, delirium also occurred frequently in patients treated in geriatric and internal / general medicine, as well as in visceral surgery. Similar prevalences were found in patients recovering from visceral surgery, reconstructive plastic surgery, cranio-maxillo-facial surgery, and oral surgery. This new finding underscores the importance of a standard delirium management guideline for use across patient groups.

The comparison of the delirium point-prevalence rate by ICD-10 diagnosis chapter and the presence of delirium in patients within and between groups partly reflected these rates. Delirious states were most frequent in patients with main diagnoses referring to the ICD-10 chapters on mental / behavioral disorders, infections, injuries, poisoning, or diseases of the nervous, circulatory, digestive, blood and endocrine /nutritional /metabolic systems. The high prevalence of delirious states in patients with diagnoses related to Chapter V (mental / 'behavioral disorders) can be explained by that chapter's direct focus on psychiatric disorders. The other diagnosis chapters refer to diseases such as infections or abnormal laboratory values, e.g., abnormal creatinine, serum sodium, glucose or potassium levels and metabolic acidosis, which are known precipitating factors of delirium $[11,61,62]$.

Our subgroup analysis by ICD-10 diagnosis chapter indicated not only that delirious patients were significantly more likely to die, but that they required roughly twice most non-delirious groups' nursing hours, ICU days, hospital stay, and overall financial expenditure per case. The one exception was the category of non-delirious patients with infections and respiratory diseases, whose ICU stays were not significantly lower (Table 2). These demonstrated negative outcomes in patients with delirium correspond with recent findings of significant differences between delirious and non-delirious patients' mortality rates $[14,19,63-65]$, ICU LOS $[14,16,19,66,67]$, hospital LOS [14, 16, 17, 19, 66, 67], nursing hours per case [68] and total cost [17, 26, 67]. The demonstrated variation in these outcomes regarding the seven top ICD-10 diagnosis groups adds to the current evidence. Such marked differences between main outcomes suggest that group-specific characteristics and risk factors influence delirium-related outcomes and consequences. Still, it remains unclear whether delirium contributes to poorer outcomes, impacts the underlying illness's trajectory [69], or simply indicates greater disease severity.

As our results show, compared to non-delirious patients, those with delirium were more often admitted from other hospitals and less frequently discharged home. In addition, they were treated in the ICU more frequently (table1). This suggests that, compared to their non-delirious counterparts, the delirious were more seriously ill or had more exacerbated functional health status impairment. Since serious disease and functional 
Table 2 In-hospital mortality, LOS in the ICU and in hospital, nursing hours and costs per case in delirious and non-delirious patients with a main diagnosis, which refers to the top-seven ICD-10 diagnoses chapters

\begin{tabular}{|c|c|c|c|c|c|c|}
\hline \multicolumn{2}{|l|}{ Outcome by ICD-10 chapter } & \multicolumn{2}{|l|}{$\begin{array}{l}\text { Non-delirious } \\
\text { (DOS < 3, ICDSC < 4) }\end{array}$} & \multirow{2}{*}{$\begin{array}{l}\text { Delirious } \\
\text { (DOS } \geq 3, \text { ICDSC } \geq 4) \\
n \text { dead }(\%)\end{array}$} & \multirow{2}{*}{$\begin{array}{l}\text { Difference } \\
\text { odds ratio (95\% Cl) }\end{array}$} & \multirow[t]{2}{*}{$p$} \\
\hline Mortality & $n$ & $n$ dead (\%) & $n$ & & & \\
\hline Diseases of circulatory system & $1^{\prime} 470$ & $41(3 \%)$ & 758 & $67(9 \%)$ & 3.38 (2.27 to 5.04$)$ & $<0.001$ \\
\hline Neoplasms & $1 ' 295$ & $36(3 \%)$ & 380 & $51(13 \%)$ & $5.42(3.48$ to 8.45$)$ & $<0.001$ \\
\hline Injury/poisoning of external cause & 446 & $12(3 \%)$ & 256 & $28(11 \%)$ & 4.44 (2.22 to 8.90$)$ & $<0.001$ \\
\hline Diseases of the digestive system & 315 & $5(2 \%)$ & 101 & $15(15 \%)$ & 10.81 (3.82 to 30.59$)$ & $<0.001$ \\
\hline Diseases of nervous system & 242 & $3(1 \%)$ & 113 & $7(6 \%)$ & 5.26 (1.33 to 20.74$)$ & 0.0177 \\
\hline Infections/parasites & 80 & $5(6 \%)$ & 78 & $22(28 \%)$ & 5.89 (2.10 to 16.52$)$ & $<0.001$ \\
\hline Diseases of respiratory system & 232 & $7(3 \%)$ & 59 & $12(20 \%)$ & 8.21 (3.07 to 21.95$)$ & $<0.001$ \\
\hline other & $1 ' 214$ & $6(0 \%)$ & 253 & $14(6 \%)$ & 11.79 (4.49 to 30.98 ) & $<0.001$ \\
\hline ICU LOS [days] & $n$ & median (95\% Cl) & $n$ & median (95\% Cl) & hazard ratio (95\% Cl) & \\
\hline Diseases of circulatory system & 331 & 1.0 (0.9 to 1.0$)$ & 384 & 3.1 (2.7 to 4.0$)$ & $0.43(0.37$ to 0.50$)$ & $<0.001$ \\
\hline Neoplasms & 174 & 0.9 (0.9 to 0.9$)$ & 147 & 2.9 (1.9 to 4.5$)$ & 0.37 (0.29 to 0.46$)$ & $<0.001$ \\
\hline Injury/poisoning of external cause & 61 & 0.9 (0.8 to 1.4$)$ & 133 & 3.7 (3.0 to 5.4$)$ & 0.47 (0.34 to 0.64$)$ & $<0.001$ \\
\hline Diseases of the digestive system & 40 & 1.0 (0.9 to 1.7$)$ & 47 & 10.8 (4.6 to 13.5$)$ & 0.28 (0.18 to 0.44$)$ & $<0.001$ \\
\hline Diseases of nervous system & 41 & 0.8 (0.7 to 0.8$)$ & 38 & $1.8(0.8$ to 7.5$)$ & $0.26(0.16$ to 0.40$)$ & $<0.001$ \\
\hline Infections/parasites & 8 & $2.0(0.9$ to -$)$ & 29 & $13.5(5.2$ to 25.1$)$ & $0.65(0.22$ to 1.90$)$ & 0.434 \\
\hline Diseases of respiratory system & 33 & 1.1 (1.0 to 2.0$)$ & 17 & $1.8(1.0$ to 15.0$)$ & 0.64 (0.34 to 1.17$)$ & 0.148 \\
\hline other & 74 & 0.9 (0.9 to 1.5$)$ & 56 & 4.9 (3.9 to 11.0$)$ & 0.34 (0.24 to 0.49$)$ & $<0.001$ \\
\hline Hospital LOS [days] & $n$ & median (95\% CI) & $n$ & median (95\% Cl) & hazard ratio (95\% CI) & \\
\hline Diseases of circulatory system & $1 ' 470$ & 8 (8 to 9$)$ & 758 & 71 (43 to - ) & 0.21 (0.18 to 0.25$)$ & $<0.001$ \\
\hline Neoplasms & $1 ' 295$ & 7 (6 to 7$)$ & 380 & 26 (22 to 37$)$ & 0.30 (0.25 to 0.35$)$ & $<0.001$ \\
\hline Injury/poisoning of external cause & 446 & 8 (7 to 9$)$ & 256 & 37 (33 to -$)$ & 0.23 (0.17 to 0.30$)$ & $<0.001$ \\
\hline Diseases of the digestive system & 315 & $6(6$ to 7$)$ & 101 & 31 (21 to - ) & 0.26 (0.19 to 0.36$)$ & $<0.001$ \\
\hline Diseases of nervous system & 242 & 7 (6 to 7$)$ & 113 & $25(15$ to -$)$ & 0.31 (0.23 to 0.43$)$ & $<0.001$ \\
\hline Infections/parasites & 80 & 7 (6 to 12$)$ & 78 & $58(43$ to -$)$ & 0.18 (0.11 to 0.30$)$ & $<0.001$ \\
\hline Diseases of respiratory system & 232 & $8(7$ to 10$)$ & 59 & 17 (14 to -$)$ & $0.42(0.27$ to 0.65$)$ & $<0.001$ \\
\hline other & $1 ' 309$ & 5 (5 to 6 ) & 312 & 19 (15 to 24$)$ & 0.32 (0.27 to 0.38$)$ & $<0.001$ \\
\hline Nursing hours [in hours] & n & median (25\%; $75 \%$ quantiles) & $n$ & median (25\%; $75 \%$ quantiles) & median difference $(95 \% \mathrm{Cl})$ & \\
\hline Diseases of circulatory system & $1^{\prime} 470$ & $39.9(20.3 ; 73.4)$ & 758 & $119.2(63.5 ; 226.4)$ & 79.2 (70.1 to 88.4$)$ & $<0.001$ \\
\hline Neoplasms & $1 ' 295$ & $36.9(21.3 ; 67.7)$ & 380 & $101.2(42.1 ; 192.6)$ & $63.9(48.3$ to 79.5$)$ & $<0.001$ \\
\hline Injury/poisoning of external cause & 446 & $44.1(24.8 ; 74.5)$ & 256 & $102.9(51.5 ; 195.8)$ & $58.8(42.2$ to 75.5$)$ & $<0.001$ \\
\hline Diseases of the digestive system & 315 & $28.9(19.6 ; 57.8)$ & 101 & $100.2(37.2 ; 326.3)$ & 71.3 (25.1 to 117.5$)$ & 0.00255 \\
\hline Diseases of nervous system & 242 & $27.9(18.5 ; 45.5)$ & 113 & $71.7(37.6 ; 122.7)$ & 43.9 (28.4 to 59.5$)$ & $<0.001$ \\
\hline Infections/parasites & 80 & $31.8(17.2 ; 67.2)$ & 78 & $128.2(62.9 ; 298.3)$ & 95.8 (74.1 to 117.6$)$ & $<0.001$ \\
\hline Diseases of respiratory system & 232 & $38.8(19.4 ; 73.6)$ & 59 & $66.5(41.6 ; 120.3)$ & 27.8 (18.2 to 37.3$)$ & $<0.001$ \\
\hline other & 1'309 & $25.1(15.9 ; 46.1)$ & 312 & $62.6(29.0 ; 142.0)$ & $37.6(27.6$ to 47.6$)$ & $<0.001$ \\
\hline Cost [in thousand CHF] & $n$ & median (25\%; $75 \%$ quantiles) & n & median (25\%; $75 \%$ quantiles) & median difference $(95 \% \mathrm{Cl})$ & \\
\hline Diseases of circulatory system & $1 ' 470$ & $20.4(11.6 ; 40.6)$ & 758 & $48.3(23.3 ; 79.7)$ & 27.7 (23.0 to 32.4$)$ & $<0.001$ \\
\hline Neoplasms & $1 ' 295$ & $13.7(7.2 ; 27.4)$ & 380 & $35.3(15.4 ; 63.7)$ & 21.5 (17.8 to 25.3$)$ & $<0.001$ \\
\hline Injury/poisoning of external cause & 446 & $15.2(9.0 ; 25.2)$ & 256 & $34.9(19.6 ; 67.7)$ & 19.5 (15.6 to 23.4$)$ & $<0.001$ \\
\hline Diseases of the digestive system & 315 & $11.3(6.8 ; 19.8)$ & 101 & $31.0(13.0 ; 90.0)$ & 19.7 (9.7 to 29.7$)$ & $<0.001$ \\
\hline Diseases of nervous system & 242 & $10.9(7.8 ; 18.3)$ & 113 & $20.6(13.5 ; 44.0)$ & 9.8 (6.6 to 13.0$)$ & $<0.001$ \\
\hline Infections/parasites & 80 & $9.9(6.1 ; 19.0)$ & 78 & $35.4(16.6 ; 97.4)$ & 24.4 (18.1 to 30.7$)$ & $<0.001$ \\
\hline Diseases of respiratory system & 232 & $12.4(7.6 ; 24.8)$ & 59 & $18.8(13.1 ; 29.8)$ & 6.5 (4.2 to 8.7$)$ & $<0.001$ \\
\hline other & $1 ' 214$ & $9.2(6.0 ; 15.9)$ & 253 & $16.6(9.0 ; 32.6)$ & $7.4(4.7$ to 10.1$)$ & $<0.001$ \\
\hline
\end{tabular}

Legend: ICU intensive care unit; LOS length of stay, missing values for LOS due to censoring are indicated with a dash (-), 


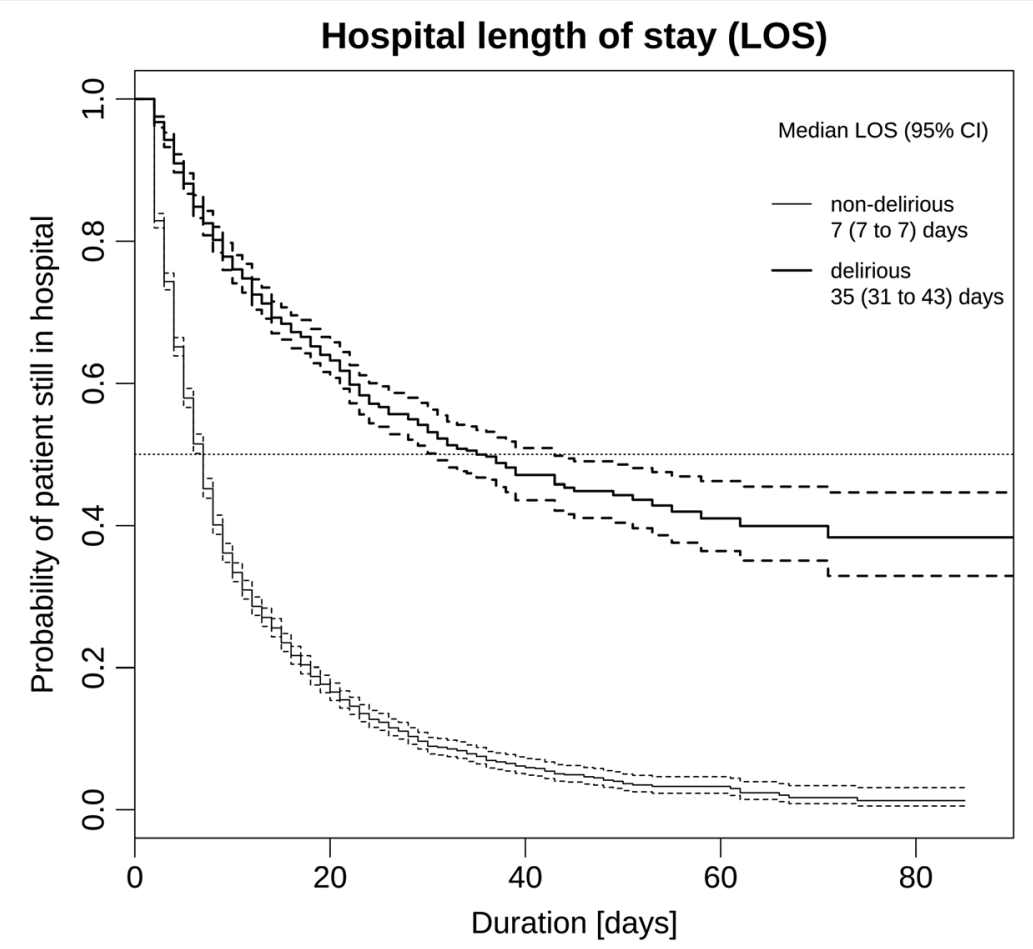

Fig. 3 Duration of the hospital length of stay in delirious and non-delirious patients

impairment are known predictors of delirium [3, 11, 12], despite controlling for all known confounders in the first set of models, which we run for the comparison of the non-delirious and delirious patients, we cannot exclude the possibility that these factors contributed to the outcome differences discussed above.

This study has a number of notable strengths and limitations. One strength is that its analyses covered all eligible patients treated in the study hospital over one full calendar year. The sample included a broad range of surgical, medical, and mixed surgical-medical patient groups - several of which, to our knowledge, were studied for the first time in this context. Two analyses were particularly important: that of the patient subgroup identified as at risk for delirium; and, within this group, the separate analysis of only the older at-risk patients by ICD-10 main diagnosis chapter. Both provided important insights regarding the occurrence of delirium in diverse subgroups. Limitations include an observational design and the inclusion of only a single center, both of which limit the generalizability of the results and allow no inferences regarding causal relations. Another limitation is that our chosen approach to identifying delirious patients - classing a patient as delirious if he/she had at least once an DOS score $\geq 3$ and / or a ICDSC score of $\geq 4$ - might have been too sensitive, i.e., it might have led to delirium rate overestimation. Further, the use of existing clinical data restricted both the number of variables and the overall adequacy of the dataset regarding our needs. This and the large sample size, for example, made a precise calculation of delirium intensity and duration unfeasible. Finally, in the study hospital, roughly 2'000 clinicians participated in delirium screening. Although these clinicians' delirium training covered interrater reliability, a smaller research team may have yielded more reliable assessment results. I.e., while the use of validated screening tools ensured that detection of patients with delirium was reliable within acceptable tolerances. Further studies, ideally of a prospective nature, will be necessary to confirm our findings.

\section{Conclusions}

The results reported here indicate not only high numbers of patients identified as at risk for a delirium but also high delirium prevalence across most patient groups. This underscores the relevance of this topic and the need for systematic delirium management to prevent, recognize, and treat delirium across patient groups.

In both the unadjusted and adjusted models, compared to the patients without delirium, delirious patients' $\geq$ 65 year had a significantly higher mortality rate and longer ICU and hospital LOS. They also required more nursing hours and generated much higher cost per case. In the subgroup analysis conducted by ICD-10 diagnosis chapter, for the unadjusted models, each diagnostic group's delirious patients had worse outcomes compared to those with no delirium. However, considering that, as discussed 
above, the current study cannot indicate causality, is it essential to test these findings with a study design that allows causal inferences.

Our subgroup analyses highlighted striking variations in delirium period-prevalence across patient groups. Several of these differences, e.g., the frequent occurrence of delirium in cardiac surgery or geriatric patients, support previous findings. One new finding - which requires further attention - is the high prevalence of delirium in radiotherapy, visceral surgery, reconstructive plastic surgery, and cranio-maxillo-facial or oral surgery patients - all groups who have thus far fallen either outside or only marginally within the scope of clinical delirium management.

In the subgroup analysis according to the ICD-10 diagnosis chapters, patient diagnoses referring to known delirium precipitating factors, e.g., infection/parasites, injury, poisoning, or endocrine /nutritional /metabolic diseases, were linked with elevated delirium prevalence. Therefore, in addition to patients currently in the focus of standard delirium management (i.e., ICU, cardiac and orthopaedic patients), it is recommended to expand that focus to include those treated in care centers for radiotherapy, visceral surgery, reconstructive plastic surgery, cranio-maxillo-facial and oral surgery.

Finally, the used approach described above to identify patients at risk for a delirium, timely screening, detection and identification of delirious patients can easily be added to standard clinical practice. From a scientific perspective, this approach allows quick classification of patients into three groups with significant and clinically relevant outcomes: (1) those not at risk, for whom delirium screening is unnecessary; (2) those at risk and screened, who do not develop a delirious state; and (3) those at risk and screened and who develop a delirious state.

\section{Additional file}

Additional file 1: Components of the delirium management protocol. (PDF $101 \mathrm{~kb}$ )

\section{Acknowledgements}

We thank the study hospital, the University Hospital Zurich, for the financial support of this project with its own funds.

\section{Funding}

None third-part funding. This study was funded by hospital funds, in form of human resources and time (working hours) allocated for this project.

\section{Availability of data and materials}

The data that support the findings of this study are available from the University Hospital Zurich; restrictions apply to the availability of these data, which were used under license for the current study, and so are not publicly available. Data are also available from the authors upon reasonable request and with permission of the University Hospital Zurich.

\section{Authors' contributions}

All authors entitled to authorship made substantial contributions to the manuscript (see list below) and read and approved the manuscript. Study concept and design: MSch, AR, SB. Acquisition of data: RSp, MSch. Data cleaning / data validation: MSch, JB, MLS, RSch. Integrity of the data, accuracy of the data analysis: MSch, RSch (both had access to all of the data in the study). Statistical analysis: RSch, MSch. Interpretation of the data: MSch, RSch, AR. Drafting of the manuscript: MSch, RSch, AR. Critical revision of the manuscript for important intellectual content: MSch, AR, RSch, SB, JB, MLS, DGN, US, DB, JJ, RSp. Study supervision: DGN, US, JJ, DB.

\section{Ethics approval and consent to participate}

This study (PB_2016-01264) was approved by the responsible ethics board of the Kantonale Ethikkommission des Kanton Zurich and carried out in accordance with the Declaration of Helsinki, taking into consideration local regulations and standards.

\section{Consent for publication}

Not applicable.

\section{Competing interests}

The authors declare that they have no competing interests.

\section{Publisher's Note}

Springer Nature remains neutral with regard to jurisdictional claims in published maps and institutional affiliations.

\section{Author details}

${ }^{1}$ Nursing Science, Faculty of Medicine, Department of Public Health, University of Basel, Bernoullistr. 28, 4056 Basel, Switzerland. ${ }^{2}$ Directorate of Nursing/MTT, Insel Gruppe, University Hospital Inselspital, Bern, Freiburgstr. 44a, 3010 Bern, Switzerland. ${ }^{3}$ School of Health Professions, Institute of Nursing, Zurich University of Applied Science, Technikumstr. 81, P.O. Box, 8401, Winterthur, Switzerland. ${ }^{4}$ Clinical Trial Unit, Institute of Social and Preventive Medicine, University of Bern, Finkenhubelweg 11, 3012 Bern, Switzerland. ${ }^{5}$ Virginia Tech, Department of Entomology (MC0319), 170 Drillfield Drive, Blacksburg, VA 24061, USA. ${ }^{6}$ Department of Psychiatry and Psychotherapy, University Hospital Zurich, Raemistr. 100, 8091 Zurich, Switzerland. 7 Center for Gender Variance, University Hospital Basel, Spitalstrasse 21, 4056 Basel, Switzerland. ${ }^{8}$ Division of Neurology, University Hospital Zurich, Raemistr. 100, 8091 Zurich, Switzerland. ${ }^{9}$ Institute of Anesthesiology, University of Zurich and University Hospital Zurich, Raemistrasse 100, 8091 Zurich, Switzerland. ${ }^{10}$ Nursing Department, Balgrist University Hospital, Forchstrasse 340, 8008 Zurich, Switzerland. ${ }^{11}$ Nursing and Allied Health Care Professions Office, University Hospital Zurich, Raemistr. 100, 8091 Zurich, Switzerland.

Received: 9 July 2017 Accepted: 1 July 2018

Published online: 13 July 2018

\section{References}

1. Meagher DJ, Maclullich AM, Laurila JV. Defining delirium for the international classification of diseases, 11th revision. J Psychosom Res. 2008;65(3):207-14.

2. Meagher DJ, Morandi A, Inouye SK, Ely W, Adamis D, Maclullich AJ, Rudolph JL, Neufeld K, Leonard M, Bellelli G, et al. Concordance between DSM-IV and DSM-5 criteria for delirium diagnosis in a pooled database of 768 prospectively evaluated patients using the delirium rating scale-revised-98. BMC Med. 2014;12:164.

3. Inouye SK, Westendorp RG, Saczynski JS. Delirium in elderly people. Lancet. 2014;383(9920):911-22.

4. Cole MG, You Y, McCusker J, Ciampi A, Belzile E. The 6 and 12 month outcomes of older medical inpatients who recover from delirium. Int J Geriatr Psychiatry. 2008;23(3):301-7.

5. Meagher DJ, Leonard M, Donnelly S, Conroy M, Adamis D, Trzepacz PT. A longitudinal study of motor subtypes in delirium: frequency and stability during episodes. J Psychosom Res. 2012;72(3):236-41.

6. Rudiger A, Begdeda H, Babic D, Kruger B, Seifert B, Schubert M, Spahn DR, Bettex D. Intra-operative events during cardiac surgery are risk factors for the development of delirium in the ICU. Crit Care. 2016;20:264.

7. Mehta S, Cook D, Devlin JW, Skrobik Y, Meade M, Fergusson D, Herridge M, Steinberg M, Granton J, Ferguson N, et al. Prevalence, risk factors, and outcomes of delirium in mechanically ventilated adults. Crit Care Med. 2015;43(3):557-66. 
8. Morandi A, Jackson JC, Ely EW. Delirium in the intensive care unit. Int Rev Psychiatry. 2009;21(1):43-58.

9. Pandharipande P, Cotton BA, Shintani A, Thompson J, Pun BT, Morris JA Jr, Dittus R, Ely EW. Prevalence and risk factors for development of delirium in surgical and trauma intensive care unit patients. J Trauma. 2008;65(1):34-41.

10. Morandi A, Jackson JC. Delirium in the intensive care unit: a review. Neurol Clin. 2011;29(4):749-63.

11. Ahmed S, Leurent B, Sampson EL. Risk factors for incident delirium among older people in acute hospital medical units: a systematic review and metaanalysis. Age Ageing. 2014;43(3):326-33.

12. Zaal IJ, Devlin JW, Peelen LM, Slooter AJ. A systematic review of risk factors for delirium in the ICU. Crit Care Med. 2015;43(1):40-7.

13. Hsieh SJ, Soto GJ, Hope AA, Ponea A, Gong MN. The association between acute respiratory distress syndrome, delirium, and in-hospital mortality in intensive care unit patients. Am J Respir Crit Care Med. 2015;191(1):71-8.

14. Zhang Z, Pan L, Ni H. Impact of delirium on clinical outcome in critically ill patients: a meta-analysis. Gen Hosp Psychiatry. 2013;35(2):105-11.

15. Gleason LJ, Schmitt EM, Kosar CM, Tabloski P, Saczynski JS, Robinson T, Cooper Z, Rogers SO Jr, Jones RN, Marcantonio ER, et al. Effect of delirium and other major complications on outcomes after elective surgery in older adults. JAMA Surg. 2015;150(12):1134-40.

16. Beckmann S, Schubert M, Burkhalter H, Dutkowski P, De Geest S. Postoperative delirium after liver transplantation is associated with increased length of stay and lower survival in a prospective cohort. Prog Transplant. 2017;27(1):23-30.

17. Zywiel MG, Hurley RT, Perruccio AV, Hancock-Howard RL, Coyte PC, Rampersaud YR. Health economic implications of perioperative delirium in older patients after surgery for a fragility hip fracture. J Bone Joint Surg Am. 2015;97(10):829-36.

18. Kiely DK, Marcantonio ER, Inouye SK, Shaffer ML, Bergmann MA, Yang FM, Fearing MA, Jones RN. Persistent delirium predicts greater mortality. J Am Geriatr Soc. 2009;57(1):55-61.

19. Maniar HS, Lindman BR, Escallier K, Avidan M, Novak E, Melby SJ, Damiano MS, Lasala J, Quader N, Rao RS, et al. Delirium after surgical and transcatheter aortic valve replacement is associated with increased mortality. J Thorac Cardiovasc Surg. 2016;151(3):815-823.e811-812.

20. Koster S, Hensens AG, van der Palen J. The long-term cognitive and functional outcomes of postoperative delirium after cardiac surgery. Ann Thorac Surg. 2009;87(5):1469-74.

21. van den Boogaard M, Schoonhoven L, Evers AW, van der Hoeven JG, van Achterberg T, Pickkers P. Delirium in critically ill patients: impact on long-term health-related quality of life and cognitive functioning. Crit Care Med. 2012;40(1):112-8

22. MacLullich AM, Beaglehole A, Hall RJ, Meagher DJ. Delirium and long-term cognitive impairment. Int Rev Psychiatry. 2009;21(1):30-42.

23. Pandharipande PP, Girard TD, Jackson JC, Morandi A, Thompson JL, Pun BT, Brummel NE, Hughes CG, Vasilevskis EE, Shintani AK, et al. Long-term cognitive impairment after critical illness. N Engl J Med. 2013;369(14):1306-16.

24. Hshieh TT, Saczynski J, Gou RY, Marcantonio E, Jones RN, Schmitt E, Cooper Z, Ayres D, Wright J, Travison TG, et al. Trajectory of functional recovery after postoperative delirium in elective surgery. Ann Surg. 2017;265(4):647-65.

25. Morandi A, Davis D, Fick DM, Turco R, Boustani M, Lucchi E, Guerini F, Morghen S, Torpilliesi T, Gentile S, et al. Delirium superimposed on dementia strongly predicts worse outcomes in older rehabilitation inpatients. J Am Med Dir Assoc. 2014:15(5):349-54.

26. Milbrandt EB, Deppen S, Harrison PL, Shintani AK, Speroff T, Stiles RA, Truman B, Bernard GR, Dittus RS, Ely EW. Costs associated with delirium in mechanically ventilated patients. Crit Care Med. 2004;32(4):955-62.

27. Leslie DL, Marcantonio ER, Zhang Y, Leo-Summers L, Inouye SK. One-year health care costs associated with delirium in the elderly population. Arch Intern Med. 2008;168(1):27-32.

28. Voellinger R, Stiefel F, Michaud L, Michel P, Dorogi Y, Burnand B, Berney A. Implementation of guidelines on delirium in a general hospital: a beforeafter study of their impact on caregivers' knowledge and clinical skills. Schweizer Archiv fur Neurologie und Psychiatrie. 2011;162(1):31-4.

29. Martin J, Heymann A, Basell K, Baron R, Biniek R, Burkle H, Dall P, Dictus C, Eggers $V$, Eichler I, et al. Evidence and consensus-based German guidelines for the management of analgesia, sedation and delirium in intensive careshort version. Ger Med Sci. 2010;8:Doc02.

30. Ely EW, Stephens RK, Jackson JC, Thomason JW, Truman B, Gordon S, Dittus RS, Bernard GR. Current opinions regarding the importance, diagnosis, and management of delirium in the intensive care unit: a survey of 912 healthcare professionals. Crit Care Med. 2004;32(1):106-12.

31. Balas MC, Burke WJ, Gannon D, Cohen MZ, Colburn L, Bevil C, Franz D, Olsen KM, Ely EW, Vasilevskis EE. Implementing the awakening and breathing coordination, delirium monitoring/management, and early exercise/mobility bundle into everyday care: opportunities, challenges, and lessons learned for implementing the ICU pain, agitation, and delirium guidelines. Crit Care Med. 2013;41(9 Suppl 1):S116-27.

32. NCGC: DELIRIUM: diagnosis, prevention and management. Clinical Guideline, 103. National Institute for Health and Clinical Excellence (NICE), National Clinical Guideline Centre (NCGC); 2010;103:1-447.

33. Zaubler TS, Murphy K, Rizzuto L, Santos R, Skotzko C, Giordano J, Bustami R, Inouye SK. Quality improvement and cost savings with multicomponent delirium interventions: replication of the hospital elder life program in a community hospital. Psychosomatics. 2013;54(3):219-26.

34. Hshieh T, Yue J, Oh E, Puelle M, Dowal S, Travison T, Inouye SK. Effectiveness of multicomponent nonpharmacological delirium interventions: a meta-analysis. JAMA Intern Med. 2015;175(4):512-20.

35. Schubert M, Boettger S, Rudiger A, Spirig R. Delir-path: detect evaluate control inpatient risk factors, prevent and treat hospital acquired deliriums (health services research project). Zurich: University Hospital Zurich; 2013. p. 1-22.

36. Schubert M, Fröhlich MR, Liem E, Schwab H, Burmeister B, Brenner G, Spirig R. Delirmanagement im Intensivpflegebereich. Intensiv Fachzeitschrift für Intensivpflege und Anästhesie. 2012;20(5):254-8.

37. Boettger S, Knopfel S, Schubert M, Garcia Nunez D, Plichta MM, Klaghofer R, Jenewein J. Pipamperone and delirium: a preliminary evaluation of its effectiveness in the management of delirium and its subtypes. Swiss Med Wkly. 2017;147:w14471.

38. Boettger S, Nunez DG, Meyer R, Richter A, Fernandez SF, Rudiger A, Schubert $M$, Jenewein J. Delirium in the intensive care setting: a reevaluation of the validity of the CAM-ICU and ICDSC versus the DSM-IV-TR in determining a diagnosis of delirium as part of the daily clinical routine. Palliat Support Care. 2017;15(6):675-83.

39. Boettger S, Nunez DG, Meyer R, Richter A, Fernandez SF, Rudiger A, Schubert $M$, Jenewein J. Delirium in the intensive care setting and the Richmond agitation and sedation scale (RASS): drowsiness increases the risk and is subthreshold for delirium. J Psychosom Res. 2017;103:133-9.

40. Boettger S, Nunez DG, Meyer R, Richter A, Schubert M, Jenewein J. Subsyndromal delirium in the intensive care setting: phenomenological characteristics and discrimination of subsyndromal delirium versus no and full-syndromal delirium. Palliat Support Care. 2018;16(1):3-13.

41. Boettger S, Nunez DG, Meyer R, Richter A, Schubert M, Meagher D, Jenewein J. Brief assessment of delirium subtypes: psychometric evaluation of the delirium motor subtype scale (DMSS)-4 in the intensive care setting. Palliat support Care. 2017;15(5):535-43.

42. Boettger S, Meyer R, Richter A, Fernandez SF, Rudiger A, Schubert M, Jenewein J, Nunez DG. Screening for delirium with the Intensive Care Delirium Screening Checklist (ICDSC): Symptom profile and utility of individual items in the identification of delirium dependent on the level of sedation. Palliat Support Care. 2018:1-8. https://doi.org/10.1017/ S1478951518000202. [Epub ahead of print].

43. Schubert M, Stalder I, Saxer S. Comparison of items and scores of the ePAACC first assessment in cardiological and cardiac surgery patients with or without delirium: a nested case-control study [Vergleich von items und scores des ePA-AC@ Erstassessments bei kardiologischen und herzchirurgischen Patientinnen und Patienten mit und ohne Delir: eine eingebettete fall-Kontroll-Studie]. Pflegewissenschaft. 2017;9(10):458-67.

44. Hasemann W, Tolson D, Godwin J, Spirig R, Frei IA, Kressig RW. A before and after study of a nurse led comprehensive delirium management programme (DemDel) for older acute care inpatients with cognitive impairment. Int J Nurs Stud. 2016;53:27-38.

45. Bush SH, Kanji S, Pereira JL, Davis DH, Currow DC, Meagher DJ, Rabheru K, Wright DK, Bruera E, Agar M, et al. Treating an established episode of delirium in palliative care: expert opinion and review of the current evidence base with recommendations for future development. J Pain Symptom Manag. 2014;48(2):231-48.

46. Fann JR, Hubbard RA, Alfano CM, Roth-Roemer S, Katon WJ, Syrjala KL. Pre- and post-transplantation risk factors for delirium onset and severity in patients undergoing hematopoietic stem-cell transplantation. J Clin Oncol. 2011;29(7):895-901. 
47. Schuurmans MJ, Shortridge-Baggett LM, Duursma SA. The delirium observation screening scale: a screening instrument for delirium. Res Theory Nurs Pract. 2003;17(1):31-50.

48. Sessler CN, Gosnell MS, Grap MJ, Brophy GM, O'Neal PV, Keane KA Tesoro EP, Elswick RK. The Richmond agitation-sedation scale: validity and reliability in adult intensive care unit patients. Am J Respir Crit Care Med. 2002;166(10):1338-44.

49. Bergeron N, Dubois MJ, Dumont M, Dial S, Skrobik Y. Intensive care delirium screening checklist: evaluation of a new screening tool. Intensive Care Med. 2001;27(5):859-64.

50. Detroyer E, Clement PM, Baeten N, Pennemans M, Decruyenaere M, Vandenberghe J, Menten J, Joosten E, Milisen K. Detection of delirium in palliative care unit patients: a prospective descriptive study of the delirium observation screening scale administered by bedside nurses. Palliat Med. 2014;28(1):79-86.

51. van Velthuijsen EL, Zwakhalen SM, Warnier RM, Mulder WJ, Verhey FR, Kempen Gl. Psychometric properties and feasibility of instruments for the detection of delirium in older hospitalized patients: a systematic review. Int J Geriatr Psychiatry. 2016;31(9):974-89.

52. Gusmao-Flores D, Figueira Salluh Jl, Chalhub RA, Quarantini LC. The confusion assessment method for the intensive care unit (CAM-ICU) and intensive care delirium screening checklist (ICDSC) for the diagnosis of delirium: a systematic review and meta-analysis of clinical studies. Crit Care. 2012;16(4):R115.

53. Quan H, Li B, Couris CM, Fushimi K, Graham P, Hider P, Januel JM, Sundararajan V. Updating and validating the Charlson comorbidity index and score for risk adjustment in hospital discharge abstracts using data from 6 countries. Am J Epidemiol. 2011;173(6):676-82.

54. BFS: Statistik der stationären Betriebe des Gesundheitswesens, Medizinische Statistik der Krankenhäuser. In. Neuchatél: Bundesamt für Statistik, Abteilung Bevölkerung und Beschäftigung; 1997: 1-43 + Anhang.

55. SGI-SSMI: Minimaler Datensatz der SGI (MDSI) In. Edited by (KPK) KP. Basel; 2013: 1-30.

56. Baumberger D, Kuehne G, Hieber S: LEP Making nurse' work visible LEP Nursing 3.3. In., vol. 2, March 2007 edn. St. Gallen: LEP-AG; 2007: 1-10.

57. Hagar $Y$, Dukic V. Comparison of hazard rate estimation in R. Colorado: University of Colorado; 2015. p. 1-38.

58. R Development Core Team: A language and environment for statistical computing: R Foundation for Statistical Computing. Vienna: Vienna University of Economics and Business. http://www.R-project.org. Accessed 2016.

59. Brown $\mathrm{CH}$. Delirium in the cardiac surgical ICU. Curr Opin Anaesthesiol. 2014;27(2):117-22.

60. Koster S, Hensens AG, Schuurmans MJ, van der Palen J. Prediction of delirium after cardiac surgery and the use of a risk checklist. Eur J Cardiovasc Nurs. 2013;12(3):284-92.

61. Tomlinson EJ, Phillips NM, Mohebbi M, Hutchinson AM. Risk factors for incident delirium in an acute general medical setting: a retrospective case control study. J Clin Nurs. 2017;26(5-6):658-67.

62. Bellelli G, Morandi A, Di Santo SG, Mazzone A, Cherubini A, Mossello E, Bo M, Bianchetti A, Rozzini R, Zanetti E, et al. "delirium day": a nationwide point prevalence study of delirium in older hospitalized patients using an easy standardized diagnostic tool. BMC Med. 2016;14:106.

63. Aliberti S, Bellelli G, Belotti M, Morandi A, Messinesi G, Annoni G, Pesci A. Delirium symptoms during hospitalization predict long-term mortality in patients with severe pneumonia. Aging Clin Exp Res. 2015;27(4):523-31.

64. Klein Klouwenberg PM, Zaal IJ, Spitoni C, Ong DS, van der Kooi AW, Bonten MJ, Slooter AJ, Cremer OL. The attributable mortality of delirium in critically ill patients: prospective cohort study. BMJ. 2014;349:96652.

65. Koster S, Hensens AG, Schuurmans MJ, van der Palen J. Consequences of delirium after cardiac operations. Ann Thorac Surg. 2012;93(3):705-11.

66. van den Boogaard M, Schoonhoven L, van der Hoeven JG, van Achterberg T, Pickkers P. Incidence and short-term consequences of delirium in critically ill patients: a prospective observational cohort study. Int J Nurs Stud. 2012; 49(7):775-83.
67. CHt B, Laflam A, Max L, Lymar D, Neufeld KJ, Tian J, Shah AS, Whitman GJ, Hogue CW. The impact of delirium after cardiac surgical procedures on postoperative resource use. Ann Thorac Surg. 2016;101(5):1663-9.

68. Weinrebe W, Johannsdottir E, Karaman M, Fusgen I. What does delirium cost?: An economic evaluation of hyperactive delirium. Z Gerontol Geriatr. 2016;49(1):52-8.

69. Fong TG, Tulebaev SR, Inouye SK. Delirium in elderly adults: diagnosis, prevention and treatment. Nat Rev Neurol. 2009;5(4):210-20.

Ready to submit your research? Choose BMC and benefit from:

- fast, convenient online submission

- thorough peer review by experienced researchers in your field

- rapid publication on acceptance

- support for research data, including large and complex data types

- gold Open Access which fosters wider collaboration and increased citations

- maximum visibility for your research: over $100 \mathrm{M}$ website views per year

At BMC, research is always in progress.

Learn more biomedcentral.com/submissions 